\title{
Priority Analysis on the Production Layout of Potato in China
}

\author{
Pengling Liu*, Yun Zhou, Kang Sun, Zhen Fang \\ College of Economics and Management, Anhui Agricultural University, Hefei 230036, China
}

Corresponding Author Email: liupengling@ahau.edu.cn

https://doi.org/10.18280/ijsdp.150712

Received: 6 May 2020

Accepted: 19 August 2020

\section{Keywords: \\ production layout of potato, priority, production concentration index (PCI), production advantage, layout planning}

\begin{abstract}
Based on the panel data 2009-2018 on 23 potato producing areas in China, this paper firstly analyzes the priority of each area in potato production layout, using the production concentration index (PCI). Then, the main factors affecting the PCI of potato were identified, and used to develop an evaluation index system (EIS) for production advantage. Through entropy method, the production advantage of each area in potato cultivation was evaluated, and ranked in descending order. Finally, the priority of each area in potato production layout was measured comprehensively, and a total of 11 areas were determined as priority areas. On this basis, several suggestions were put forward to optimize the production layout of potato in China: (1) The Chinese government should give priority to the following producing areas in the planning of potato production layout: Sichuan, Guizhou, Yunnan, and Chongqing in Northwest China; Gansu, Shaanxi, and Qinghai in Northwest China; Hebei, and Inner Mongolia in North China; Heilongjiang in Northeast China; Hubei in the winter cropping area in the south. (2) The 11 priority areas should arrange potato production as per the local situation, during the planning of crop production layout. (3) The relevant planning departments should grasp the change trend in the producing areas of potato and other water-saving crops, identify their main producing areas, and deploy water-saving crops in dry and water-deficient, which are not suitable for rice or wheat.
\end{abstract}

\section{INTRODUCTION}

With the spread of Coronavirus Disease 2019 (COVID-19), some countries have reduced or banned the export of staple food crops. This raises concerns on food security [1,2]. Being the most populous country in the world, China must give top priority to food security. It is important for the country to improve the overall food yield as per local conditions.

So far, China has basically used up the agricultural lands suitable for rice and wheat $[3,4]$. Fortunately, potato, which serves as both staple food and vegetable, could be planted in some dry and water-deficient areas unfit for rice or wheat. Potato boasts advantages of short planting cycle, high yield, and wide adaptability [5], and plays an important role in improving the family income and nutrition of farmers [6]. In 2015, China positioned potato as a staple food. Currently, potation cultivation in China features great potential, wide range, and low yield [7]. Further research is needed to optimize the layout of potation production, and improve its production efficiency and yield.

At present, potato production has been widely studied at home and abroad. But few have attempted to optimize the layout of potato production in China. In terms of production efficiency, Osipov et al. [8] analyzed the efficiency of potato production in Russia, and proved the effectiveness of technical training. Through stochastic frontier analysis (SFA), Kamau et al. [9] examined the technical efficiency and influencing factors of Irish potato production in Monroe County, Kenya. Some scholars $[10,11]$ conducted data envelopment analysis (DEA) on the efficiency and scale efficiency of potato production.

In terms of storage technology, some scholars [12, 13] explored the effects of different conditions on the antibrowning of fresh-cut potato chips, and concluded that shortterm high-oxygen pretreatment and Portulaca oleracea extract both have significant anti-browning effects. Lin et al. [14] investigated the cold reaction mechanism of potato tubers stored at low temperature, shedding light on the sugar accumulation and defense reaction of potato tubers under cold storage conditions.

In terms of production layout: Through linear programming optimization, Liu et al. [15] established a national grain production layout optimization model based on the comparative advantage index of agricultural food production (ACI), and achieved the synergy between land, water, and food. Qiao et al. [16] studied the impact of crop distribution and climate change on crop production, using the Environmental Policy Integrated Climate (EPIC) model. Davis et al. [17] derived the potential differences between 14 staple food crops in food production and water use from process-based crop moisture model and spatial interpolated yields, and reduced the water use by optimizing the crop layout. Based on the county statistics in 2000-2003, Yin et al. [18] captured the variation in China's grain production layout in the $21^{\text {st }}$ century. Lv and Sun [19] discovered that potato production in China is more and more accumulated geographically, and gradually shifts from east to west. Yang et al. [20] held that traditional potato production areas, such as the two-season cropping area in the Central Plains, and the one-season cropping area in the north, maintain a large 
comparative advantage, while the one- and two-season mixed cropping area in the southwest is gaining momentum. The above studies provide a useful reference for this research.

Based on the potato production data of China's 23 provincial administrative regions (hereinafter referred to as provinces) in 2009-2018, this paper calculates the production concentration index (PCI) of potato in each province, and comprehensively evaluates the production advantage of each potato producing area. On this basis, the authors analyzed the priority in the production layout of potato in China, identified the producing area that should be prioritized in production layout. The research results provide insights to the optimization of production layout of potato in China.

\section{PCI-BASED PRIORITY ANALYSIS}

\subsection{Study areas}

The one-season cropping area in the north mainly includes Heilongjiang, Jilin, and Liaoning in Northeast China; Shaanxi, Ningxia, Gansu, Qinghai, and Xinjiang in Northwest China; Hebei, Shanxi, and Inner Mongolia in North China. The twoseason cropping area in the Central Plains mainly includes Zhejiang, Anhui, and Jiangxi. The one- and two-season mixed cropping area in the southwest mainly include Guizhou, Yunnan, Sichuan, Tibet, and Chongqing. The winter cropping area in the south mainly include Hubei, Hunan, Fujian, Guangdong, and Guangxi.

\subsection{Methodology}

The PCI, the main index of this research, was defined as the ratio of potato yield in a province to the nationwide yield. The PCI of a province $P C I_{i t}$ can be calculated by Eq. (1).

First, the regression equation for the correlation between $P C I_{i t}$ and time t was established to analyze the change trend of $P C I_{i t}$ in each province. Then, the potato producing areas in
China were classified and sorted based on the significance of the correlation.

$$
P C I_{i t}=\frac{Q_{i t}}{\sum_{i=1}^{n} Q_{i t}} \times 100
$$

\subsection{PCI change trend}

Table 1 presents the regression results on the change trend of $P C I_{i t}$ in each province. It can be seen that, in 2009-2018, the Chinese provinces differed significantly in the change trend of $P C I_{i t}$.

Based on the significance of the correlation between $P C I_{i t}$ and time in 2008-2019, the Chinese provinces were divided into the following characteristic regions of potation production:

(1) Region with significant increase

Seven provinces, namely, Hebei, Shanxi, Guangdong, Sichuan, Guizhou, Tibet, and Shaanxi, saw significant increase in $P C I_{i t}$. The annual $P C I_{i t}$ values of these provinces were added up into $P C I_{l}$. It can be seen that: the $P C I_{l}$ of the region with significance increase rose from $32.75 \%$ in 2009 to $43.56 \%$ in 2018 (as shown in Table 2); the change trend can be described as: $P C I_{1}=1.466 * T+29.078\left(R^{2}=0.922\right)$.

(2) Region with significant decrease

Ten provinces, namely, Inner Mongolia, Heilongjiang, Zhejiang, Anhui, Fujian, Hunan, Yunnan, Gansu, Ningxia, and Xinjiang witnessed significant decrease in $P C I_{i t}$. The annual $P C I_{i t}$ values of these provinces were added up into $P C I_{2}$. The change trend of this region can be expressed as: $P C I_{2}=-$ $1.477 * T+52.458\left(R^{2}=0.906\right)$.

(3) Other region (region with insignificant change)

Six provinces, namely, Liaoning, Jilin, Hubei, Guangxi, Chongqing, and Qinghai, did not seen any obvious change in $P C I_{i t}$.

Table 2 lists the PCIs of the three characteristic regions in 2009-2018.

Table 1. The change trend of $P C I_{i t}$ in Chinese provinces

\begin{tabular}{|c|c|c|c|c|c|c|c|}
\hline Province & Regression equation & $\mathbf{r}$ & $\mathbf{a}$ & Province & Regression equation & $\mathbf{r}$ & $\mathbf{a}$ \\
\hline Hebei & $P C I_{i t}=0.431 * \mathrm{~T}+1.28$ & 0.89 & $* * *$ & Guangxi & $P C I_{i t}=0.035 * \mathrm{~T}+0.80$ & 0.26 & \\
\hline Shanxi & $P C I_{i t}=0.135 * \mathrm{~T}+0.98$ & 0.92 & $* * *$ & Chongqing & $P C I_{i t}=-0.033 * \mathrm{~T}+6.85$ & -0.34 & \\
\hline Inner Mongolia & $P C I_{i t}=-0.388 * \mathrm{~T}+11.40$ & -0.87 & $* * *$ & Sichuan & $P C I_{i t}=0.300 * \mathrm{~T}+13.38$ & 0.73 & $* *$ \\
\hline Liaoning & $P C I_{i t}=-0.016 * \mathrm{~T}+2.00$ & -0.17 & & Guizhou & $P C I_{i t}=0.475^{*} \mathrm{~T}+8.84$ & 0.90 & $* * *$ \\
\hline Jilin & $P C I_{i t}=-0.087 * \mathrm{~T}+3.21$ & -0.33 & & Yunnan & $P C I_{i t}=-0.193 * \mathrm{~T}+10.20$ & -0.81 & $* * *$ \\
\hline Heilongjiang & $P C I_{i t}=-0.357 * \mathrm{~T}+7.79$ & -0.85 & $* * *$ & Tibet & $P C I_{i t}=0.002 * \mathrm{~T}+0.02$ & 0.79 & $* * *$ \\
\hline Zhejiang & $P C I_{i t}=-0.039 * \mathrm{~T}+1.37$ & -0.63 & $* *$ & Shaanxi & $P C I_{i t}=0.103 * \mathrm{~T}+3.41$ & 0.85 & $* * *$ \\
\hline Anhui & $P C I_{i t}=-0.040 * \mathrm{~T}+0.43$ & -0.85 & $* * *$ & Gansu & $P C I_{i t}=-0.204 * \mathrm{~T}+13.16$ & -0.69 & $* *$ \\
\hline Fujian & $P C I_{i t}=-0.076 * \mathrm{~T}+1.91$ & -0.78 & $* * *$ & Qinghai & $P C I_{i t}=-0.045 * \mathrm{~T}+2.28$ & -0.55 & \\
\hline Hubei & $P C I_{i t}=0.002 * \mathrm{~T}+3.72$ & 0.03 & & Ningxia & $P C I_{i t}=-0.083 * \mathrm{~T}+2.71$ & -0.94 & $* * *$ \\
\hline Hunan & $P C I_{i t}=-0.035 * \mathrm{~T}+2.20$ & -0.66 & $* *$ & Xinjiang & $P C I_{i t}=-0.061 * \mathrm{~T}+1.29$ & -0.71 & $* *$ \\
\hline Guangdong & $P C I_{i t}=0.020 * \mathrm{~T}+1.17$ & 0.59 & * & & & & \\
\hline
\end{tabular}

Table 2. The PCIs of the three characteristic regions in 2009-2018

\begin{tabular}{lccc||cccc}
\hline Year & $\begin{array}{c}\text { Region with } \\
\text { significant increase }\end{array}$ & $\begin{array}{c}\text { Region with } \\
\text { significant decrease }\end{array}$ & $\begin{array}{c}\text { Other } \\
\text { region }\end{array}$ & Year & $\begin{array}{c}\text { Region with } \\
\text { significant increase }\end{array}$ & $\begin{array}{c}\text { Region with } \\
\text { significant decrease }\end{array}$ & $\begin{array}{c}\text { Other } \\
\text { region }\end{array}$ \\
\hline 2009 & 32.75 & 49.94 & 17.32 & 2014 & 36.93 & 44.01 & 18.71 \\
2010 & 32.27 & 47.68 & 20.05 & 2015 & 38.53 & 42.10 & 19.00 \\
2011 & 31.99 & 49.74 & 18.59 & 2016 & 42.71 & 38.57 & 17.56 \\
2012 & 34.21 & 47.62 & 17.73 & 2017 & 43.18 & 38.05 & 17.65 \\
2013 & 35.28 & 46.91 & 17.47 & 2018 & 43.56 & 38.72 & 16.55 \\
\hline
\end{tabular}




\subsection{PCI-based priority}

The above analysis shows that $P C I_{i t}$ trend differed from province to province, suggesting that the layout of potato producing areas in China changed constantly in the sample period. Then, the 23 provinces were ranked by annual $P C I_{i t}$ values in 2009-2018. The rankings of each province in the 10 years were added up into the total ranking score of that province (as shown in Table 3). Next, the provinces with relatively low total ranking scores were given relatively high priority.

As shown in Table 3, the 23 provinces can be ranked by the priority in potation production layout as: Sichuan> Gansu> Guizhou> Inner Mongolia> Yunnan> Chongqing> Heilongjiang> Shaanxi> Hubei> Hebei $>$ Jilin $>$ Ningxia> Qinghai $>$ Hunan $>$ Liaoning $>$ Shanxi $>$ Fujian $>$ Guangdong $>$ Zhejiang > Guangxi $>$ Xinjiang $>$ Anhui > Tibet. The top ranked areas are mostly concentrated in the southwest and northwest, which agrees with the results of Lv Chao et al. (2019).

\section{INFLUENCING FACTORS OF PCI}

\subsection{Variable setting and data description}

The $P C I_{i t}$ of each province was explained by six variables: the PCI in the previous year, natural disaster, agricultural infrastructure, technological level, industrial structure, and non-agricultural employment. The panel data of the 23 potato producing areas were selected from statistical data like China Rural Statistical Yearbooks. The meanings and expected effects of model variables are given in Table 4.

\subsection{Model construction}

The theoretical model can be established as:

$$
\begin{aligned}
& P C I_{i t}=\alpha+\beta_{1} P C I_{i t-1}+\beta_{2} \text { Disaster }_{i t} \\
& +\beta_{3} \text { Irrigation }_{i t}+\beta_{4} \text { Techno } \log y_{i t} \\
& +\beta_{5} \text { Structure }_{i t}+\beta_{6} \text { Nonfarm }_{i t}+Z_{i} \delta+U_{i}+V_{i t}
\end{aligned}
$$

where, $i$ is the serial number of province; $t$ is year; the explained variable $P C I_{i t}$ is the PCI of potato production; $P C I_{i t-}$ I, Disaster ${ }_{i t}$, Irrigation ${ }_{i t}$, Technology $_{i t}$, Structure $_{i t}$, and Nonfarm $_{i t}$ are explanatory variables; $\alpha$ is a constant; $\beta_{1}-\beta_{6}$ are the coefficients of the six explanatory variables, respectively; $Z_{i}$ is the time-invariant individual feature; $U_{i}$ and $V_{i t}$ are intercept and disturbance, respectively.

\subsection{Results analysis}

The model estimation was carried out on StataSE14.0, using short panel data. Through Hausman test, the fixed-effects model was selected for the estimation. The estimation results are recorded in Table 5.

Table 3. The total ranking scores of Chinese provinces

\begin{tabular}{ccccccccccccc}
\hline Ranking & Province & $\mathbf{2 0 0 9}$ & $\mathbf{2 0 1 0}$ & $\mathbf{2 0 1 1}$ & $\mathbf{2 0 1 2}$ & $\mathbf{2 0 1 3}$ & $\mathbf{2 0 1 4}$ & $\mathbf{2 0 1 5}$ & $\mathbf{2 0 1 6}$ & $\mathbf{2 0 1 7}$ & $\mathbf{2 0 1 8}$ & Total ranking score \\
\hline 1 & Sichuan & 1 & 1 & 2 & 1 & 1 & 1 & 1 & 1 & 1 & 1 & 11 \\
2 & Gansu & 2 & 2 & 1 & 2 & 2 & 2 & 3 & 3 & 3 & 3 & 23 \\
3 & Guizhou & 4 & 5 & 4 & 4 & 3 & 3 & 2 & 2 & 2 & 2 & 31 \\
4 & Inner Mongolia & 3 & 3 & 3 & 3 & 4 & 5 & 5 & 5 & 5 & 4 & 40 \\
5 & Yunnan & 5 & 4 & 5 & 5 & 5 & 4 & 4 & 4 & 4 & 5 & 45 \\
6 & Chongqing & 6 & 7 & 7 & 7 & 6 & 6 & 6 & 6 & 6 & 6 & 63 \\
7 & Heilongiiang & 7 & 6 & 6 & 6 & 7 & 7 & 7 & 9 & 8 & 9 & 72 \\
8 & Shaanxi & 8 & 10 & 9 & 9 & 9 & 8 & 9 & 8 & 9 & 8 & 87 \\
9 & Hubei & 9 & 9 & 8 & 8 & 8 & 9 & 8 & 10 & 10 & 10 & 89 \\
10 & Hebei & 15 & 11 & 11 & 11 & 10 & 11 & 10 & 7 & 7 & 7 & 100 \\
11 & Jilin & 16 & 8 & 10 & 10 & 11 & 10 & 11 & 11 & 11 & 15 & 113 \\
12 & Ningxia & 10 & 12 & 12 & 12 & 12 & 12 & 13 & 14 & 14 & 12 & 123 \\
13 & Qinghai & 11 & 13 & 14 & 14 & 14 & 15 & 14 & 13 & 15 & 13 & 136 \\
14 & Hunan & 12 & 14 & 15 & 13 & 13 & 14 & 12 & 16 & 16 & 14 & 139 \\
15 & Liaoning & 13 & 15 & 13 & 16 & 17 & 13 & 15 & 15 & 13 & 16 & 146 \\
16 & Shanxi & 18 & 18 & 17 & 17 & 16 & 17 & 18 & 12 & 12 & 11 & 156 \\
17 & Fujian & 14 & 16 & 16 & 15 & 15 & 16 & 16 & 18 & 18 & 18 & 162 \\
18 & Guangdong & 20 & 17 & 20 & 18 & 19 & 20 & 20 & 17 & 17 & 17 & 185 \\
19 & Zhejiang & 19 & 20 & 18 & 19 & 19 & 19 & 19 & 19 & 19 & 19 & 190 \\
20 & Guangxi & 21 & 21 & 21 & 20 & 18 & 18 & 17 & 20 & 20 & 20 & 196 \\
21 & Xinjiang & 17 & 19 & 19 & 21 & 21 & 21 & 21 & 21 & 21 & 21 & 202 \\
22 & Anhui & 22 & 22 & 22 & 22 & 22 & 22 & 22 & 22 & 22 & 22 & 220 \\
23 & Tibet & 23 & 23 & 23 & 23 & 23 & 23 & 23 & 23 & 23 & 23 & 230 \\
\hline
\end{tabular}

Table 4. The meanings and expected effects of model variables

\begin{tabular}{cccc}
\hline Variable & Code & Meaning & Expected effect \\
\hline The PCI in the previous year & PCI $_{\text {it- }}$ & The PCI in year $t-1$ & Positive \\
Natural disaster & Disaster $_{i t}$ & Disaster-affected area & Negative \\
Agricultural infrastructure & Irrigation $_{i t}$ & Effectively irrigated area & Positive \\
Technological level & Technology $_{i t}$ & Potato yield per unit area & Positive \\
Industrial structure & Structure $_{i t}$ & Sown area ratio of potato to all crops & Positive \\
Non-agricultural employment & Nonfarm $_{i t}$ & Wage income as a proportion of net income of villagers & Negative \\
\hline
\end{tabular}


Table 5. The estimation results on panel data

\begin{tabular}{cccc}
\hline Variable & Coefficient & Standard deviation & t-value \\
\hline The PCI in the previous year & $0.3818^{* * *}$ & 0.05025 & 7.60 \\
Natural disaster & $-0.0046^{* *}$ & 0.00178 & -2.59 \\
Agricultural infrastructure & $0.0103 * * *$ & 0.00323 & 3.18 \\
Technological level & $0.0003 * * *$ & 0.00004 & 6.71 \\
Industrial structure & $10.5795^{*}$ & 5.40432 & 1.96 \\
Non-agricultural employment & -0.9809 & 0.9184 & -1.07 \\
Constant & 0.5688 & 0.44448 & 1.28 \\
\hline \multicolumn{2}{c}{ Note: $* * *, * *$, and $*$ are the significance levels of $1 \%, 5 \%$, and $10 \%$, respectively. }
\end{tabular}

As shown in Table 5, our model achieved a good fitting effect. The PCI of potato was significantly promoted by the PCI in the previous year, agricultural infrastructure, technological level, and industrial structure, and significantly suppressed by natural disaster, and non-agricultural employment.

\section{PRODUCTION ADVANTAGE-BASED PRIORITY ANALYSIS}

\subsection{Evaluation index system (EIS) for production advantage}

The production advantage of each potato producing area in China was evaluated comprehensively through the entropy method. Drawing on the above results on the factors affecting the PCI, this paper sets up an EIS for production advantage of each potato producing area, which is systematic, effective, and comparable.There are three primary indices in the EIS: technology and facility, nature and economy, and production scale. Each primary index was supported by several secondary indices. Specifically, technology and facility was decomposed into effectively irrigated area (X1) and technical level (X2); nature and economy was decomposed into industrial structure
(X3), disaster-affected area (X4), and non-agricultural employment (X5); production scale was decomposed into sown area (X6) and potato yield (X7).

\subsection{Comprehensive evaluation of production advantage}

Based on the statistics on each potato producing area in 2018, the production advantage of each area was comprehensively evaluated by entropy method. First, the weight of each index was calculated step by step (as shown in Table 6). Then, the comprehensive production advantage scores of the 23 areas were obtained one by one (as shown in Table 7).

Table 6. The entropy, diversity factor, and weight of each index

\begin{tabular}{cccc}
\hline Index & Entropy & Diversity factor & Weight \\
\hline X1 & 0.8839 & 0.1161 & 0.1674 \\
X2 & 0.9125 & 0.0875 & 0.1261 \\
X3 & 0.8512 & 0.1488 & 0.2146 \\
X4 & 0.9787 & 0.0213 & 0.0308 \\
X5 & 0.9676 & 0.0324 & 0.0467 \\
X6 & 0.8500 & 0.1500 & 0.2163 \\
X7 & 0.8627 & 0.1373 & 0.1980 \\
\hline
\end{tabular}

Table 7. The comprehensive production advantage scores in 2018

\begin{tabular}{|c|c|c|c|c|c|c|c|c|c|c|}
\hline \multirow{2}{*}{\multicolumn{2}{|c|}{ Region }} & \multirow{2}{*}{ Province } & \multicolumn{2}{|c|}{ Technology and facility } & \multicolumn{2}{|c|}{ Nature and economy } & \multicolumn{2}{|c|}{ Production scale } & \multirow{2}{*}{$\begin{array}{c}\text { Comprehensive } \\
\text { score } \\
\end{array}$} & \multirow{2}{*}{ Ranking } \\
\hline & & & Score & Ranking & Score & Ranking & Score & Ranking & & \\
\hline \multirow{11}{*}{$\begin{array}{l}\text { The one- } \\
\text { season } \\
\text { cropping } \\
\text { area in } \\
\text { the north }\end{array}$} & \multirow{5}{*}{ Northwest China } & Shaanxi & 0.0111 & 11 & 0.0175 & 6 & 0.0232 & 7 & 0.0519 & 7 \\
\hline & & Gansu & 0.0250 & 2 & 0.0318 & 2 & 0.0478 & 3 & 0.1045 & 3 \\
\hline & & Qinghai & 0.0086 & 19 & 0.0346 & 1 & 0.0084 & 13 & 0.0515 & 8 \\
\hline & & Ningxia & 0.0080 & 20 & 0.0215 & 5 & 0.0094 & 12 & 0.0389 & 10 \\
\hline & & Xinjiang & 0.0138 & 9 & 0.0052 & 19 & 0.0023 & 21 & 0.0213 & 18 \\
\hline & \multirow{3}{*}{ North China } & Hebei & 0.0214 & 3 & 0.0062 & 15 & 0.0193 & 8 & 0.0468 & 9 \\
\hline & & Shanxi & 0.0086 & 18 & 0.0108 & 10 & 0.0124 & 11 & 0.0319 & 13 \\
\hline & & Inner Mongolia & 0.0190 & 4 & 0.0114 & 9 & 0.0323 & 5 & 0.0627 & 5 \\
\hline & \multirow{3}{*}{ Northeast China } & Liaoning & 0.0099 & 15 & 0.0063 & 14 & 0.0064 & 15 & 0.0227 & 16 \\
\hline & & Jilin & 0.0175 & 6 & 0.0060 & 17 & 0.0063 & 16 & 0.0298 & 14 \\
\hline & & Heilongjiang & 0.0146 & 8 & 0.0067 & 13 & 0.0161 & 10 & 0.0375 & 11 \\
\hline \multirow{2}{*}{\multicolumn{2}{|c|}{$\begin{array}{l}\text { The two-season cropping } \\
\text { area in the Central Plains }\end{array}$}} & Zhejiang & 0.0069 & 21 & 0.0051 & 20 & 0.0035 & 20 & 0.0155 & 21 \\
\hline & & Anhui & 0.0028 & 22 & 0.0040 & 23 & 0.0009 & 22 & 0.0077 & 23 \\
\hline \multirow{5}{*}{\multicolumn{2}{|c|}{$\begin{array}{c}\text { The winter cropping area } \\
\text { in the south }\end{array}$}} & Fujian & 0.0087 & 17 & 0.0087 & 12 & 0.0047 & 18 & 0.0222 & 17 \\
\hline & & Hubei & 0.0103 & 14 & 0.0091 & 11 & 0.0172 & 9 & 0.0365 & 12 \\
\hline & & Hunan & 0.0106 & 13 & 0.0051 & 21 & 0.0075 & 14 & 0.0232 & 15 \\
\hline & & Guangdong & 0.0094 & 16 & 0.0050 & 22 & 0.0054 & 17 & 0.0199 & 19 \\
\hline & & Guangxi & 0.0019 & 23 & 0.0060 & 16 & 0.0043 & 19 & 0.0122 & 22 \\
\hline \multirow{5}{*}{\multicolumn{2}{|c|}{$\begin{array}{l}\text { The one- and two-season } \\
\text { mixed cropping area in the } \\
\text { southwest }\end{array}$}} & Chongqing & 0.0108 & 12 & 0.0229 & 4 & 0.0282 & 6 & 0.0620 & 6 \\
\hline & & Sichuan & 0.0272 & 1 & 0.0172 & 8 & 0.0613 & 1 & 0.1057 & 2 \\
\hline & & Guizhou & 0.0188 & 5 & 0.0283 & 3 & 0.0591 & 2 & 0.1062 & 1 \\
\hline & & Yunnan & 0.0161 & 7 & 0.0172 & 7 & 0.0377 & 4 & 0.0711 & 4 \\
\hline & & Tibet & 0.0125 & 10 & 0.0053 & 18 & 0.0006 & 23 & 0.0184 & 20 \\
\hline
\end{tabular}




\subsection{Production advantage-based priority}

The above analysis shows that Guizhou had the highest comprehensive score of production advantage (0.1062), while Anhui had the lowest score (0.0077). Based on the comprehensive evaluation of production advantage, the 23 Chinese provinces can be ranked by the priority in production layout as: Guizhou> Sichuan> Gansu> Yunnan> Inner Mongolia $>$ Chongqing $>$ Shaanxi $>$ Qinghai $>$ Hebei $>$ Ningxia $>$ Heilongjiang> Hubei> Shanxi> Jilin> Hunan> Liaoning> Fujian > Xinjiang > Guangdong $>$ Tibet $>$ Zhejiang $>$ Guangxi $>$ Anhui.

The top-ranking provinces mainly concentrate in Southwest and Northwest China. In Southwest China, Sichuan, Guizhou, and Yunnan ranked high in technology and facility, nature and economy, as well as production scale, a sign of strong comprehensive advantages; Chongqing also had a clear edge in nature and economy, as well as production scale. In Northwest China, Gansu, Shaanxi, Qinghai, and Ningxia boasted strong comprehensive advantages; among them, Gansu ranked in the top 3 in terms of technology and facility, nature and economy, as well as production scale; Shaanxi,
Qinghai, and Ningxia ranked among the top in terms of nature and economy.

In North China, Hebei finished the third in technology and facility, which reflects its development advantage; the advantages of Inner Mongolia lay in technology and facility, production scale, and the large area. In Northeast China, Heilongjiang occupied the eighth place in technology and facility, and thus had certain advantages.

\section{PRIORITY OF PRODUCTION LAYOUT}

\subsection{Comprehensive measurement of priority}

Drawing on the PCI-based priority and production advantage-based priority, this section comprehensively measures the priority of each potato producing area in production layout. Specifically, the rankings of each province in PCI-based priority and production advantage-based priority were added up, and the provinces with relatively low total ranking score were given relatively high priority. The results of comprehensive measurement are presented in Table 8 .

Table 8. The results of comprehensive measurement

\begin{tabular}{|c|c|c|c|c|c|c|}
\hline \multicolumn{2}{|c|}{ Region } & \multirow{2}{*}{$\begin{array}{c}\text { Province } \\
\text { Shaanxi }\end{array}$} & \multirow{2}{*}{$\begin{array}{c}\begin{array}{c}\text { PCI-based } \\
\text { ranking }\end{array} \\
8\end{array}$} & \multirow{2}{*}{$\begin{array}{c}\begin{array}{c}\text { Production advantage- } \\
\text { based ranking }\end{array} \\
7\end{array}$} & \multirow{2}{*}{$\begin{array}{c}\begin{array}{c}\text { Total ranking } \\
\text { score }\end{array} \\
15\end{array}$} & \multirow{2}{*}{$\begin{array}{c}\begin{array}{c}\text { Comprehensive } \\
\text { ranking }\end{array} \\
7\end{array}$} \\
\hline \multirow{11}{*}{$\begin{array}{l}\text { The one- } \\
\text { season } \\
\text { cropping area } \\
\text { in the north }\end{array}$} & \multirow{5}{*}{ Northwest China } & & & & & \\
\hline & & Gansu & 2 & 3 & 5 & 3 \\
\hline & & Qinghai & 13 & 8 & 21 & 10 \\
\hline & & Ningxia & 12 & 10 & 22 & 12 \\
\hline & & Xinjiang & 21 & 18 & 39 & 19 \\
\hline & \multirow{3}{*}{ North China } & Hebei & 10 & 9 & 19 & 9 \\
\hline & & Shanxi & 16 & 13 & 29 & 14 \\
\hline & & Inner Mongolia & 4 & 5 & 9 & 4 \\
\hline & \multirow{3}{*}{ Northeast China } & Liaoning & 15 & 16 & 31 & 16 \\
\hline & & Jilin & 11 & 14 & 25 & 13 \\
\hline & & Heilongjiang & 7 & 11 & 18 & 8 \\
\hline \multirow{2}{*}{\multicolumn{2}{|c|}{$\begin{array}{c}\text { The two-season cropping area in } \\
\text { the Central Plains }\end{array}$}} & Zhejiang & 19 & 21 & 40 & 20 \\
\hline & & Anhui & 22 & 23 & 45 & 23 \\
\hline \multirow{5}{*}{\multicolumn{2}{|c|}{$\begin{array}{l}\text { The winter cropping area in the } \\
\text { south }\end{array}$}} & Fujian & 17 & 17 & 34 & 17 \\
\hline & & Hubei & 9 & 12 & 21 & 10 \\
\hline & & Hunan & 14 & 15 & 29 & 14 \\
\hline & & Guangdong & 18 & 19 & 37 & 18 \\
\hline & & Guangxi & 20 & 22 & 42 & 21 \\
\hline \multirow{5}{*}{\multicolumn{2}{|c|}{$\begin{array}{l}\text { The one- and two-season mixed } \\
\text { cropping area in the southwest }\end{array}$}} & Chongqing & 6 & 6 & 12 & 6 \\
\hline & & Sichuan & 1 & 2 & 3 & 1 \\
\hline & & Guizhou & 3 & 1 & 4 & 2 \\
\hline & & Yunnan & 5 & 4 & 9 & 4 \\
\hline & & Tibet & 23 & 20 & 43 & 22 \\
\hline
\end{tabular}

\subsection{Results analysis}

As shown in Table 8 , the 23 provinces can be ranked by priority of production layout as Sichuan> Guizhou> Gansu> Inner Mongolia = Yunnan $>$ Chongqing $>$ Shaanxi $>$ Heilongjiang $>$ Hebei $>$ Hubei $=$ Qinghai $>$ Ningxia $>$ Jilin $>$ Hunan $=$ Shanxi $>$ Liaoning $>$ Fujian $>$ Guangdong $>$ Xinjiang $>$ Zhejiang $>$ Guangxi $>$ Tibet $>$ Anhui.

Eleven provinces were among the top ten of the comprehensive ranking: Sichuan, Guizhou, Gansu, Inner Mongolia, Yunnan, Chongqing, Shaanxi, Heilongjiang, Hebei, Hubei, and Qinghai. These prioritized areas concentrate in
Southwest and Northwest China.

In Southwest China, Sichuan, Guizhou, Yunnan, and Chongqing appeared in the top six whether in the PCI-based ranking or production advantage-based ranking. In Northwest China, Shaanxi, Gansu, and Qinghai were among the top 10 in the comprehensive ranking; Gansu even reached the third place. In addition, Hebei and Inner Mongolia in North China, Heilongjiang in Northeast China, and Hubei in the winter cropping area in the south, also ranked among the top 10 in the comprehensive ranking; these provinces have strong development potential, judging by PCI or production advantage. 


\section{CONCLUSIONS}

Based on the 2009-2018 production data in 23 potato producing areas in China, this paper analyzes the priority of each area in the production layout of potato through PCI trend analysis. In addition, the main factors affecting the PCI of potato were identified, and used to set up an EIS for production advantage. On this basis, the production advantage of each area was evaluated by the entropy method, and ranked in descending order. Finally, the priorities of all the 23 areas in production layout were comprehensively measured, and a total of 11 areas were identified as the priority areas.

In view of the above results, this paper puts forward several suggestions to optimize the production layout of potato in China:

(1) The Chinese government should give priority to the following producing areas in the planning of potato production layout: Sichuan, Guizhou, Yunnan, and Chongqing in Northwest China; Gansu, Shaanxi, and Qinghai in Northwest China; Hebei, and Inner Mongolia in North China; Heilongjiang in Northeast China; Hubei in the winter cropping area in the south.

(2) The 11 priority areas should arrange potato production as per the local situation, during the planning of crop production layout.

(3) The relevant planning departments should grasp the change trend in the producing areas of potato and other watersaving crops, identify their main producing areas, and deploy water-saving crops in dry and water-deficient, which are not suitable for rice or wheat.

\section{ACKNOWLEDGMENT}

This work was supported by the Philosophy and Social Sciences Planning Fund, Anhui Province, China (Grant No.: AHSKZ2018D02)

\section{REFERENCES}

[1] Erokhin, V., Gao, T. (2020). Impacts of COVID-19 on trade and economic aspects of food security: Evidence from 45 developing countries. International Journal of Environmental Research and Public Health, 17(16): 5775. https://doi.org/10.3390/ijerph17165775

[2] Barichello, R. (2020). The COVID-19 pandemic: Anticipating its effects on Canada's agricultural trade. Canadian Journal of Agricultural Economics/Revue Canadienne d'agroeconomie, 68(2): 219-224. https://doi.org/10.1111/cjag.12244

[3] Ye, S., Song, C., Shen, S., Gao, P., Cheng, C., Cheng, F., Wan, C., Zhu, D. (2020). Spatial pattern of arable landuse intensity in China. Land Use Policy, 99: 104845. https://doi.org/10.1016/j.landusepol.2020.104845

[4] Ge, D., Long, H., Zhang, Y., Ma, L., Li, T. (2018). Farmland transition and its influences on grain production in China. Land Use Policy, 70: 94-105. https://doi.org/10.1016/j.landusepol.2017.10.010

[5] Stokstad, E. (2019). The new potato. Science, 363(6427): 574-577. https://doi.org/10.1126/science.363.6427.574

[6] Ebrahim, M. (2019). Adoption of improved potato varieties and its impact on household nutrition: Evidence from Emba Alaje Woreda, northern Ethiopia (Doctoral dissertation, Bahir Dar University). https://hdl.handle.net/10568/102173

[7] Tang, J., Wang, J., Fang, Q., Dayananda, B., Yu, Q., Zhao, P., Yin, H., Pan, X. (2019). Identifying agronomic options for better potato production and conserving water resources in the agro-pastoral ecotone in North China. Agricultural and Forest Meteorology, 272: 91-101. https://doi.org/10.1016/j.agrformet.2019.04.001

[8] Osipov, V., Zhevora, S., Yanushkina, N. (2019). Efficiency of potato production: analysis of variation and differentiation of regions of the Russian Federation. In IOP Conference Series: Earth and Environmental Science, 274(1): 012060. https://doi.org/10.1088/17551315/274/1/012060

[9] Kamau, P.N., Gathungu, G.K., Mwirigi, R.N. (2020). Technical efficiency of irish potato (Solanum tuberosum L.) production in Molo Sub County, Kenya. Asian Journal of Advances in Agricultural Research, 13(3): 19. https://doi.org/10.9734/ajaar/2020/v13i330104

[10] Mardani, M., Salarpour, M. (2015). Measuring technical efficiency of potato production in Iran using robust data envelopment analysis. Information Processing in Agriculture, 2(1): 6-14. https://doi.org/10.1016/j.inpa.2015.01.002

[11] Mengui, K.C., Oh, S., Lee, S.H. (2019). The technical efficiency of smallholder irish potato producers in santa subdivision, cameroon. Agriculture, 9(12): 259. https://doi.org/10.3390/agriculture9120259

[12] Liu, X., Wang, T., Lu, Y., Yang, Q., Li, Y., Deng, X., Liu, Y., Du, X., Qiao, L., Zheng, J. (2019). Effect of high oxygen pretreatment of whole tuber on anti-browning of fresh-cut potato slices during storage. Food Chemistry, 301: 125287. https://doi.org/10.1016/j.foodchem.2019.125287

[13] Liu, X., Yang, Q., Lu, Y., Li, Y., Li, T., Zhou, B., Qiao, L. (2019). Effect of purslane (Portulaca oleracea L.) extract on anti-browning of fresh-cut potato slices during storage. Food Chemistry, 283: 445-453. https://doi.org/10.1016/j.foodchem.2019.01.058

[14] Lin, Q., Xie, Y., Guan, W., Duan, Y., Wang, Z., Sun, C. (2019). Combined transcriptomic and proteomic analysis of cold stress induced sugar accumulation and heat shock proteins expression during postharvest potato tuber storage. Food Chemistry, 297: 124991. https://doi.org/10.1016/j.foodchem.2019.124991

[15] Liu, Y., Wang, S., Chen, B. (2019). Optimization of national food production layout based on comparative advantage index. Energy Procedia, 158: 3846-3852. https://doi.org/10.1016/j.egypro.2019.01.862

[16] Qiao, J., Yu, D., Wang, Q., Liu, Y. (2018). Diverse effects of crop distribution and climate change on crop production in the agro-pastoral transitional zone of China. Frontiers of Earth Science, 12(2): 408-419. https://doi.org/10.1007/s11707-017-0665-9

[17] Davis, K.F., Rulli, M.C., Seveso, A., D’Odorico, P. (2017). Increased food production and reduced water use through optimized crop distribution. Nature Geoscience, 10(12): 919-924. https://doi.org/10.1038/s41561-0170004-5

[18] Yin, P., Fang, X., Tian, Q., Ma, Y. (2006). The changing regional distribution of grain production in China in the 21 st century. Journal of Geographical Sciences, 16(4): 396-404. https://doi.org/10.1007/s1 1442-006-0402-x

[19] Lv, C., Sun, G.F. (2019). Study on the characteristics and 
driving factors of production regional distribution for potato in china-Based on the panel data of the main production areas. Chinese Journal of Agricultural Resources and Regional Planning, 40(6): 34-41.

[20] Yang, Y.D., Luo, Q.Y., Wang, D.L., Liu, Y., Lun, R.Q.
(2018). Influencing factors of potato planting spatial structure in China. Chinese Journal of Agricultural Resources and Regional Planning, 39(2): 76-81. https://doi.org/10.7621/cjarrp.1005-9121.20180211 